\title{
Xylem anatomical adjustments prioritize hydraulic efficiency over safety as Norway spruce trees grow taller
}

\author{
Angela Luisa Prendin (iD ${ }^{1,5}$, Stefan Mayr (iD ${ }^{2}$, Barbara Beikircher (iD ${ }^{2}$, Georg von Arx (iD 3,4 \\ and Giai Petit iD 1
}

\begin{abstract}
${ }^{1}$ Department TeSAF-Department of Territorio e Sistemi Agro-Forestali, Università degli Studi di Padova, viale dell'Università 16, 35020, Legnaro (PD), Italy; ${ }^{2}$ Institut für Botanik, Universität Innsbruck, Sternwartestraße 15 A-6020, Innsbruck, Austria; ${ }^{3}$ Swiss Federal Institute for Forest, Snow and Landscape Research WSL, Zürcherstrasse 111, 8903, Birmensdorf, Switzerland; ${ }^{4}$ Climatic Change and Climate Impacts, Institute for Environmental Sciences, 66 Boulevard Carl-Vogt, 1205, Geneva, Switzerland; ${ }^{5}$ Corresponding author (angelaluisa.prendin@studenti.unipd.it) (10) orcid.org/0000-0002-5809-7314 (1) orcid.org/0000-0002-3319-4396 (1) orcid.org/0000-0002-1423-3927 (1) orcid.org/0000-00028566-4599 (10) orcid.org/0000-0002-6546-7141
\end{abstract}

Received September 11, 2017; accepted May 16, 2018; published online June 15, 2018; handling Editor Jordi Martinez-Vilalta

As a tree grows taller, the increase in gravitational pressure and path length resistance results in lower water potentials at a given flow rate and higher carbon construction costs to transport a given amount of water to the leaves. We investigated how hydraulic safety and efficiency are coordinated under the constraints of higher cavitation risks and higher carbon construction costs with increasing tree height. We combined measurements of xylem tracheid anatomical traits with the vulnerability to drought-induced embolism and hydraulic conductivity of the apical shoots of 2- to 37-m tall Picea abies trees growing at two sites in the Dolomites (Italian Eastern Alps). We found that the theoretical hydraulic conductivity of the apical shoots increased with tree height at both sites $(P<0.001)$ as a result of an increase in either total tracheid number or mean hydraulic diameter. The xylem water potential inducing $50 \%$ loss of apical conductance significantly increased from small $(-4.45 \pm 0.20 \mathrm{MPa})$ to tall trees $(-3.65 \pm 0.03 \mathrm{MPa})(P=0.007)$. The more conductive xylem at the treetop of taller trees allows the full compensation for the height-related hydraulic constraints and minimizes the additional carbon costs of transporting water over a longer path length. The corresponding increase in vulnerability to cavitation shows that hydraulic efficiency is prioritized over safety during height growth.

Keywords: hydraulic conductivity, hydraulic limitations, $P_{50}$, safety-efficiency trade-off, tracheid lumen diameter, tree height.

\section{Introduction}

Trees are long-living organisms that continuously increase in size during ontogeny. The development of taller statures can be beneficial on the one hand, as it increases crown exposure to more direct sunlight. On the other hand, the increased height implies higher maintenance costs of living body mass and can induce some important height-related constraints to water transport, with negative consequences for the trees' gas exchange and carbon balance (Meinzer et al. 2011).

The increase in tree height implies that more conduits need to be produced to connect the absorbing roots to the transpiring leaves along a longer hydraulic path. Yet, trees need to maintain a positive carbon balance, well beyond basic metabolic needs for growth and defense. Consequently, the investment in new biomass allocated to the different organs has to account for the effects of (i) increased body size on the carbon costs associated to the maintenance of living tissues and the construction of new biomass (Meinzer et al. 2011), (ii) increased path length on total hydraulic resistance (i.e., on xylem efficiency) (Ryan and Yoder 1997) and (iii) gravity imposing a reduction in xylem water potential (i.e., a risk of xylem embolism formation) equal to $-0.01 \mathrm{MPa} \mathrm{m}^{-1}$ (Koch et al. 2004).

Growing taller thus results in a progressive increase in carbon costs to maintain an efficient and safe xylem transport system to 
sustain leaf transpiration and thus carbon assimilation. In general, safe xylem avoids (i) disruption of the water columns by air seeding via pits (Tyree and Sperry 1989) and (ii) implosion of water-filled conduits at low water potentials via cell wall reinforcement (Hacke et al. 2001a, Zhang et al. 2016), whereas an efficient xylem is characterized by a high hydraulic conductance.

Water transport from roots to leaves is constrained by the frictional forces imposed by cell wall, pit and pit membrane surfaces (i.e., hydraulic resistance). According to the Hagen-Poiseuille law, the hydraulic resistance $\left(R_{\mathrm{H}}\right)$ of a capillary tube is proportional to its length $(I)$ and inversely proportional to the fourth power of its lumen diameter (d) (Tyree and Ewers 1991):

$$
R_{H}=\frac{128 \eta l}{\pi \sum d^{4}}
$$

with $\eta$ being the dynamic viscosity of water $\left(0.001 \mathrm{~Pa} \cdot \mathrm{s}^{\circ}\right.$ at $20^{\circ}$ C).

Total hydraulic resistance from roots to leaves would thus increase with tree height (Ryan and Yoder 1997) unless either the number or the conduit diameter $(d)$ is adjusted axially (Petit and Anfodillo 2009).

According to the theoretical model of West, Brown and Enquist (hereafter WBE) (West et al. 1999), $d$ varies predictably along the longitudinal stem/branch axis. This model does not capture important characteristics of the xylem transport system such as the development of non-conductive heartwood (Petit and Anfodillo 2009), or occurrence of distal furcation in terminal twigs (McCulloh and Sperry 2005, Savage et al. 2010), yet it has the merit of emphasizing the implications of axial variation in xylem conduit diameter for plant hydraulic performance. The WBE model predicts axial scaling of conduit diameter compatible with empirical observations (Anfodillo et al. 2013). Xylem conduits are reported to increase in diameter $(d)$ with the distance from the stem/branch apex according to a power scaling with an exponent converging to the value of $b \sim 0.2$ irrespective of species, age, size and environment (Petit et al. 2008, Anfodillo et al. 2013, Prendin et al. 2017a). Such a scaling would theoretically minimize the effect of height on the total hydraulic resistance (R $R_{\text {CUM }}$; West et al. 1999), confining most of $R_{\text {CUM }}$ within a short distance from the apex. Therefore, even if $R_{\text {CUM }}$ still slightly increases with increasing path length (Mäkelä and Valentine 2006), it can be considered nearly independent of the total tree height (West et al. 1999, Petit and Anfodillo 2009, Petit et al. 2010). This rather stable pattern of axial conduit widening has been suggested to be a key feature allowing the evolution of tall plants (Enquist 2003, Anfodillo et al. 2006, Olson et al. 2014).

In addition, it has been argued that such axial configurations are an optimal solution because they minimize the total amount of carbon needed for wall construction of the xylem conduits, and optimize the hydraulic safety of the system (Mencuccini et al. 2007) as smaller and probably safer conduits (i.e., more resistant to cavitation) (Hacke and Sperry 2001, Sperry et al. 2006, Willson and Jackson 2006, Larter et al. 2017, Nardini et al. 2017) are concentrated towards the stem apex where tension is highest (i.e., water potentials are most negative) (Venturas et al. 2017). Resistance to air seeding has been most often related to geometrical characteristics of pits (e.g., size and density), which in turn seemed to scale axially along the stem and, therefore, with the conduit diameter (Lazzarin et al. 2016). Since apical conduits are very important for both efficiency and safety of the whole xylem transport system, it can be expected that the most hydraulically effective adjustments to cope with changing growth conditions will occur in this region, without greatly affecting the total carbon budget for the total xylem biomass production. In any case, whatever the modifications are, they would be adaptive if they increase the chance of survival by guaranteeing the maintenance of a functional balance between water transport and leaf transpiration to attain a positive carbon balance. In this respect, no species has evolved xylem architecture that is both highly conductive and very resistant against embolism formation (Gleason et al. 2016). This suggests that xylem modifications are unlikely to increase both hydraulic efficiency and safety, but will more likely prioritize one or the other.

In tall trees, hydraulic and carbon limitations increase because of the negative effects of (i) gravity on the xylem water potential and (ii) the total path length on $R_{\text {CUM }}$ and the cost of xylem construction. Xylem conduits at the stem apex have been reported to increase with total tree height (Petit et al. 2008, Olson et al. 2014), thus suggesting an increase in the specific hydraulic conductivity with tree height (i.e., hydraulic conductivity per unit of xylem surface area). On the contrary, other studies report xylem resistance to cavitation increases with tree height, thus suggesting that safety is prioritized in taller trees (Burgess and Dawson 2007, Ambrose et al. 2009, Domec et al. 2009). However, only one study took measurements from branches sampled in the upper canopy of trees of different sizes (Ambrose et al. 2009), whereas in all other studies, branches were sampled at different heights along the stem, thus potentially presenting anatomical adjustments related to the different positions within the crown (Bettiati et al. 2012).

In this study, we investigated the anatomical and hydraulic properties of the apical leader shoots of Norway spruce trees varying in height from 2 to $37 \mathrm{~m}$ to test the following hypotheses: (i) both anatomy and hydraulics of the xylem vary with tree height as a consequence of size-related limitations to water transport or construction costs; (ii) xylem conductivity increases, to maintain the functional balance between water transport and leaf transpiration, and possibly resistance to cavitation decreases in taller trees. In particular, we performed anatomical and hydraulic measurements at a fixed distance from the apex to eliminate the effect of axial trends in xylem anatomy and hydraulic properties of the apical shoot. 


\section{Materials and methods}

\section{Study sites and selected trees}

We selected two study sites in the Dolomites, Eastern Italian Alps, both at approximately $1650 \mathrm{~m}$ above sea level at Cinque Torri (Cortina d'Ampezzo, BL: $46^{\circ} 27^{\prime} \mathrm{N}, 12^{\circ} \mathrm{O} 8^{\prime} \mathrm{E}$ ), the forest is characterized by mixed and open clumps of Larix decidua Miller and Picea abies Karst. trees on a south-facing shallow calcareous soil. At Pian de Sire (Lorenzago di Cadore, BL: $46^{\circ} 50^{\prime} \mathrm{N}, 12^{\circ} 59^{\prime}$ $\mathrm{E})$, the forest is a monospecific Norway spruce stand on a southeast facing deep calcareous soil. The climate in both areas is typical of the south-eastern Alpine region. According to the nearest meteorological station at Cortina d'Ampezzo, mean annual temperature is $6.3^{\circ} \mathrm{C}$ and total annual precipitation around $1200 \mathrm{~mm}$, mostly occurring during summer and early autumn.

At the end of September 2014, we profited from forest logging operations to collect fresh apical shoots from $36 P$. abies individuals ranging from 2 to $37 \mathrm{~m}$ in height and from 2 to $57 \mathrm{~cm}$ in diameter at breast height (Figure 1). At each site, trees were selected to cover homogeneously the tree height range. Each tree was standing at least $6 \mathrm{~m}$ apart to the nearest individual. Sampled apical shoots were $40 \mathrm{~cm}$ long with ages varying between 1 and 5 years at the upper end, and between 1 and 8 years at the lower end. Immediately after tree felling, apical shoots were cut from the main stem under water, wrapped in moist tissue paper and stored in a plastic bag inside a cool box. Shoots were then transported to the laboratory and frozen at $-18^{\circ} \mathrm{C}$ until analysis. For each apical shoot, we used the uppermost $10 \mathrm{~cm}$ for the anatomical analyses and the consecutive for hydraulic measurements segment (between 10 and $40 \mathrm{~cm}$ ).

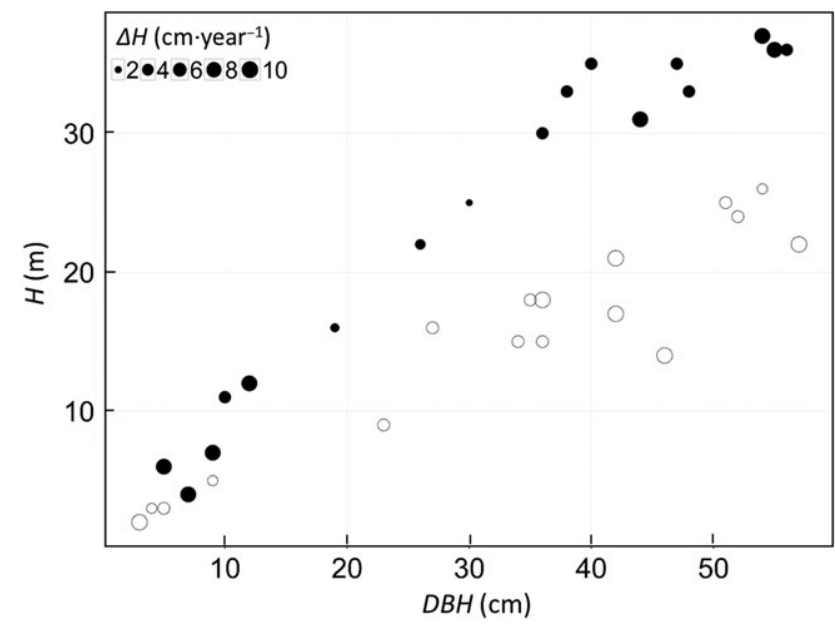

Figure 1. Variation of diameter at breast height $(D B H)$ and height $(H)$ of the sampled Picea abies trees from Cinque Torri (open symbols) and Pian de Sire (filled symbols). Point size reflects the annual elongation rate $(\Delta H)$ estimated based on the number of rings at $10 \mathrm{~cm}$ distance from the stem apex.

\section{Anatomical analysis}

Anatomical analyses were conducted on the lower/proximal part of the segments (see below) following standard protocols (von Arx et al. 2016). Entire cross sections of 10-12 $\mu \mathrm{m}$ thickness were cut with a rotary microtome (RM2245, Leica, Heidelberg, Germany). Sections were stained with safranin and astrablue ( $1 \%$ and $0.5 \%$ in distilled water, respectively), permanently fixed with Eukitt (BiOptica, Milan, Italy), and then photographed using a digital automated microscope (D-sight, Menarini Diagnostic, Florence, Italy).

Images were analyzed using ROXAS v3.0.31 (von Arx and Dietz 2005, von Arx and Carrer 2014, Prendin et al. 2017b) for the following xylem anatomical features: (i) total xylem area $(X A)$, (ii) number of tracheids $(C n)$, (iii) cell wall thickness (CWT), (iv) weighted average of hydraulic diameter (Dh) assessed as

$$
D h=\left(\frac{\sum d^{4}}{n}\right)^{0.25}
$$

where $d$ is the diameter of the $n$-conduit (Tyree and Zimmermann 2002), and (v) the fifth percentile of the cell wall reinforcement $(t / b)^{2}$ (Hacke et al. 2001a), where $t$ is the double-cell wall thickness and $b$ is the lumen diameter of the $n$th conduit measured perpendicularly to the double-cell wall, corresponding to the widest and most implosion-prone tracheids. We also estimated the theoretical hydraulic conductivity $\left(\mathrm{Kh}_{\mathrm{TH}}\right)$ for the entire xylem area (at $10 \mathrm{~cm}$ from the apex) according to the Hagen-Poiseuille law (Eq. (1)) (Tyree and Zimmermann 2002), and theoretical xylem specific conductivity $\left(K S_{T H}=K h_{T H / A X}\right.$, where subscript $A X$ is the xylem area). Measurements for a total of $>1.5$ million individual tracheids were produced.

\section{Vulnerability curves}

Frozen shoots were left overnight in a cooling room at $4{ }^{\circ} \mathrm{C}$ to let xylem water thaw slowly. Samples for vulnerability analyses were debarked and the opposing end of each shoot cut and trimmed under cold water using specialized pruning and wood carving knives. Samples were then fixed in a $28 \mathrm{~cm}$ custom-built rotor in a Sorvall RC-5 centrifuge (Thermo Fisher Scientific, Waltham, MA, USA), and were left un-flushed prior to sample conductance measurements, as maximum sample conductance ( $\left.K h_{\text {MAX }}\right)$ does not commonly differ between flushed and unflushed samples in conifers (Delzon et al. 2010).

Vulnerability curves (VCs) were generated using the Cavitron (Cochard 2002, Cochard et al. 2013) following the standard method given in Beikircher et al. (2010). VCs were assessed after repeated measurements of the sample's hydraulic conductance $(K h)$ while exposed to progressively more negative xylem pressures induced by increasing rotational speed.

The percentage loss of conductance $(P L C)$ was calculated from the ratio of the actual $(K h)$ to maximum (i.e., initial) conductance of the sample (KhMAX) (Cochard 2002) 


$$
P L C=100 *\left(1-\frac{K h}{\left(K h_{\text {MAX }}\right)}\right)
$$

PLC was then plotted against the applied negative xylem pressure by using a sigmoidal fitting function (Pammenter and Van der Willigen 1998). Curves were fitted for each sample and xylem water potential $(\Psi)$ corresponding to $P L C=12 \%\left(P_{12}\right)$, $P L C=50 \%\left(P_{50}\right)$ and $P L C=88 \%\left(P_{88}\right)$ extracted.

Specific hydraulic conductivity $(K s)$ was measured as

$$
K s=\frac{F}{\Delta \Psi} * \frac{L}{A x}
$$

where $F\left(\mathrm{~m}^{3} \mathrm{~s}^{-1}\right)$ is the flow rate, $\Delta \Psi$ is the pressure applied $(\mathrm{MPa}), L(\mathrm{~m})$ is the sample length and $A x$ is the xylem's crosssectional area $\left(\mathrm{m}^{2}\right)$.

\section{Statistical analyses}

The relationships among tree height, anatomical traits and $P_{50}$ were assessed with $\log _{10}$-transformed data to comply with assumptions of normality and homoscedasticity (Zar 2010, Zuur et al. 2010). The relationship between different traits and tree height was fitted using linear regression with $P_{50}, K h_{T H}, D h$ and $\mathrm{Cn}$ as dependent variables, and height $(H)$, site and the interactions between the two variables as independent variables. Linear regression was also used to test the relationship among $\mathrm{K} h_{\mathrm{TH}}$, $K h_{\text {MAX }}$ and $P_{50}$. All analyses were performed with $\mathrm{R}$ version 3.1.1 (R Development Core Team 2014).

\section{Results}

\section{Height-dependent modifications of xylem anatomical traits}

The anatomical analyses revealed several changes related to tree height. Mean hydraulic tracheid diameter $(D h)$ of the leader shoot at $10 \mathrm{~cm}$ from the apex varied between 10.92 and $14.88 \mu \mathrm{m}$. In particular, at Cinque Torri $D h$ significantly increased with tree height $(H)\left(R^{2}=0.46, P=0.001\right)$, while at Pian de Sire, the relationship was not significant $(P=0.835)$ (Figure $2 \mathrm{a}$ and Table 1 ). Instead, the number of tracheids $(C n)$ significantly increased with $H$ at Pian de Sire $\left(R^{2}=0.38 ; P=\right.$ 0.004 ), and not at Cinque Torri $(P=0.299)$ (Figure $2 b$ and Table 1). Overall, these height-related trends in $C n$ and $D h$ seem to be independent as the two parameters were not correlated $(P=0.50)$. In addition, the theoretical hydraulic conductivity $\left(K h_{T H}\right)$, increased with $H$ at both sites (Pian de Sire: $R^{2}=0.39$, $P=0.004$; Cinque Torri: $R^{2}=0.22, P=0.034$; see Figure S2 available as Supplementary Data at Tree Physiology Online), while the theoretical xylem specific conductivity $\left(K s_{T H}\right)$ increased with $H$ in Cinque Torri site $\left(R^{2}=0.24, P=0.026\right)$. Lastly, we found a marginally significant reduction in the cell wall reinforcement $(t / b)^{2}$ with increasing $H(P=0.060)$ and no significant trend between growth rate and $\mathrm{H}(P=0.754)$.
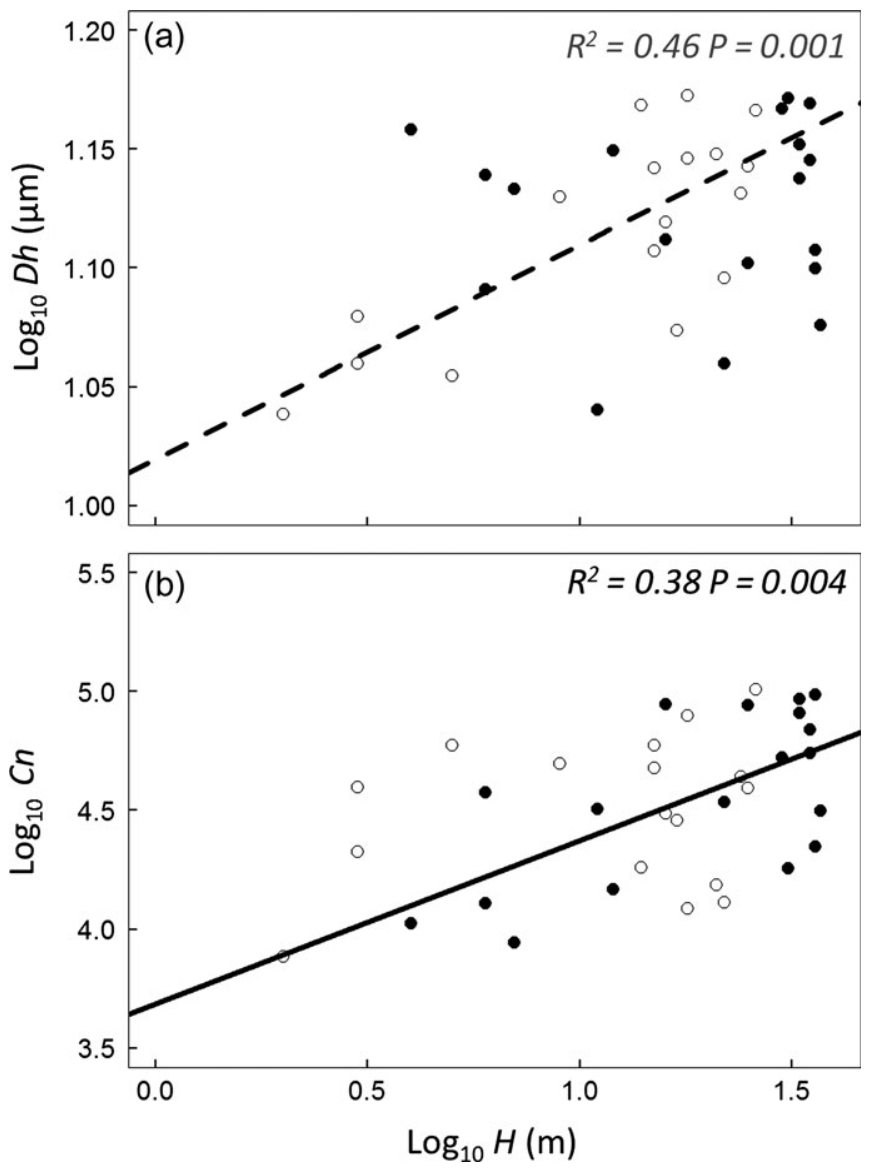

Figure 2. Relationships of (a) mean hydraulic diameter (Dh) and (b) total conduit number $(\mathrm{Cn})$ vs tree height $(H)$. Filled symbols with solid lines represent samples from Pian de Sire, open symbols with dashed lines represent samples from Cinque Torri (only significant regressions lines shown; see Table 1 for details). All data $\log _{10}$-transformed to meet model assumptions.

\section{Height-related changes in hydraulic properties}

VCs showed the typical sigmoidal shape reported for the studied species (e.g., Mayr et al. 2003) (Figure 3). The xylem pressure at $50 \%$ loss of hydraulic conductance $\left(P_{50}\right)$ varied across trees from $-3.28 \mathrm{MPa}$ to $-5.98 \mathrm{MPa}$ ( $H$ from 2 to $37 \mathrm{~m}$ ), with overall mean $P_{50}=-4.20(\sigma=0.69) \mathrm{MPa}$. We found a significant negative relationship between $\log _{10} H$ and $\log _{10} P_{50}$ in Pian de Sire and Cinque Torri $(P=0.013$ and $P=0.041$, respectively, Figure 4), indicating that $P_{50}$ becomes less negative with increasing tree height. However, $H$ explained only $20-25 \%$ of the total variance in $P_{50}$. Comparing the three smallest and three tallest trees from each site, we found $P_{50}$ varied from $-4.45 \pm$ $0.20 \mathrm{MPa}(H=7.67 \pm 1.67)$ to a maximum of $-3.77 \pm$ $0.08 \mathrm{MPa}(H=36.00 \pm 0.58)$ at Pian de Sire, and from $-4.22 \pm 0.12 \mathrm{MPa}(H=3.67 \pm 0.67 \mathrm{~m})$ to $-3.65 \pm 0.03 \mathrm{MPa}$ $(H=25.00 \pm 0.58 \mathrm{~m})$ at Cinque Torri (Figure 3).

We found a significant relationship between $K h_{\mathrm{MAX}}$ and $K h_{\mathrm{TH}}$ $\left(R^{2}=0.44, P<0.001\right)$, with $K h_{\mathrm{TH}}$ being slightly lower than $K h_{\text {MAX }}$ (see Figure S1 available as Supplementary Data at Tree 
Table 1. Results of the linear regressions of $P_{50}, K h_{\mathrm{TH}}, D h$ and $C n$ with $H$ and site (Pian de Sire and Cinque Torri). All continuous variables $\log _{10}$-transformed to meet model assumptions.

\begin{tabular}{|c|c|c|c|c|}
\hline & $\log _{10} P_{50}(-\mathrm{MPa})$ & $\log _{10} K h_{\mathrm{TH}}\left(\mathrm{m}^{4} \mathrm{MPa}^{-1} \mathrm{~s}^{-1}\right)$ & $\log _{10} D h(\mu \mathrm{m})$ & $\log _{10}(C n)$ \\
\hline Pian de Sire & $0.78 \pm 0.06^{* * *}$ & $-8.89 \pm 0.30^{* * *}$ & $1.02 \pm 0.03^{* * *}$ & $3.69 \pm 0.28^{* * *}$ \\
\hline $\log _{10} H(m)$ : Pian de Sire & $-0.12 \pm 0.04^{*}$ & $0.75 \pm 0.23^{* *}$ & $0.01 \pm 0.03$ & $0.68 \pm 0.22^{* *}$ \\
\hline Cinque Torri & $-0.08 \pm 0.07$ & $0.29 \pm 0.40$ & $-0.06 \pm 0.04^{*}$ & $0.56 \pm 0.36$ \\
\hline $\log _{10} H(m)$ : Cinque Torri & $0.02 \pm 0.06$ & $-0.22 \pm 0.32$ & $0.05 \pm 0.04^{*}$ & $-0.45 \pm 0.30$ \\
\hline
\end{tabular}

Estimates are means \pm 1 SE. ${ }^{*} P<0.05,{ }^{* *} P<0.01$ and ${ }^{* * *} P<0.001$

Physiology Online). Both parameters were significantly related to $P_{50}\left(K h_{\text {MAX }}\right.$ vs $P_{50}: R^{2}=0.33, P<0.001 ; K h_{\mathrm{TH}}$ vs $P_{50}: R^{2}=$ $0.59, P<0.001$; Figure 4). However, we did not find a correlation between hydraulically measured $\log _{10} K s$ and $\log _{10} H$ $(P=0.686)$.

\section{Discussion}

In this study, we performed anatomical and hydraulic measurements of the apical xylem of Norway spruce trees varying in height from 2 to $37 \mathrm{~m}$. In general, both anatomical (Anfodillo et al. 2006, Petit et al. 2011) and hydraulic measurements were equivalent to literature data (Mayr et al. 2002, 2003, 2007, Beikircher et al. 2010). Nevertheless, we observed significant height-related trends in anatomical and hydraulic traits. Both the number of tracheids $(C n)$ and their hydraulic diameter $(D h)$ at the apex increased with tree height $(H)$ (Figure 2) but did not co-vary. The apex of taller trees at the two sites had either wider or more tracheids and consequently achieved a higher hydraulic conductivity $\left(K h_{\mathrm{TH}}\right)$ than smaller trees. In contrast, the apical resistance to cavitation decreased from small to tall trees, with $P_{50}$ differing on average by more than $1 \mathrm{MPa}$ (Figure 4).

Our results fit the concept that biophysical constraints, which negatively affect the water transport of roots to leaves, increase with tree height (Ryan and Yoder 1997). Such constraints could intensify water stress conditions due to soil drought because they impose higher xylem tensions due to both gravity and increased total xylem resistance. Moreover, they are irreversible and thus different from soil drought conditions, as tree height (and its related hydraulic limitations) cannot diminish, at least without apical dieback.

The observed anatomical adjustments occurring at the stem apical level in taller trees likely plays a fundamental role in the general carbon and hydraulic economies in trees. Moreover, they are consistent with a previous report of increasing conduit diameter at the stem apex with increasing tree height (Olson et al. 2014). Due to the axial widening of xylem conduits, a considerable part of the total hydraulic resistance is confined to the stem apex (Petit and Anfodillo 2009), thus making this minor portion of the total root-to-leaf path length the hydraulic bottleneck of the entire xylem architecture. Although widening alone does not completely eliminate the negative effect of path length (Mäkelä and Valentine 2006) on total hydraulic resistance, further minor anatomical adjustments at the stem apex would allow full compensation (Figure 5). That is, the magnitude of the required xylem modifications at the level of stem apex is nearly negligible for the total carbon budget while optimizing the total conductance of the whole plant. To further explore this important aspect we ran a model simulation to test differences in total hydraulic resistance $\left(R_{\text {CUM }}\right)$ between a small $(H=2 \mathrm{~m})$ and a tall tree $(H=$ $37 \mathrm{~m}$ ), both characterized by a tracheid widening factor (scaling exponent of $b=0.15$ that is among the lowest reported in the literature, e.g., Petit et al. 2011). Without anatomical adjustments at the stem apex, widening alone would not fully compensate the path length effect in the tall tree and $R_{\text {CUM }}$ would be 3.4 times higher than in the small one. Instead, if $D h$ at apex increased according to our observations at the Cinque Torri site $(D h$ increasing from 10.92 to $14.88 \mu \mathrm{m}$ at a fixed distance of $L=$ $10 \mathrm{~cm}$ from the apex), the compensation would become full and nearly full (i.e., only 1.2 times higher $R_{\mathrm{CUM}}$ ), in the case that tracheids no longer increase in diameter below $10 \mathrm{~m}$ from the apex, the so-called plateau effect (Becker et al. 2003, Mencuccini et al. 2007, Petit et al. 2010) (Figure 5). In short, full compensation is guaranteed in taller trees by simply producing wider tracheids at the top of the xylem path length, the first vascular elements below the apex and further below, continuing to increase conduit diameter according to the usual widening pattern. This is in agreement with a recent study on ash trees which highlights that under drier conditions, leaf-specific conductivity is maintained while the carbon allocation to the current year xylem is reduced by producing fewer but wider vessels (Petit et al. 2016).

Our results suggest that trees with taller statures become exposed to a conditional trade-off between hydraulic efficiency and safety. The prioritization of apical xylem efficiency in tall trees seems to be the only way to overcome the negative effects of longer path lengths on the total hydraulic resistance and xylem construction costs to maintain a sufficient water transport to sustain leaf transpiration and, therefore, survival. However, it could also be argued that taller trees invest more into efficiency to promote axial growth and escape from shading by competing neighbors, while small trees already grow under more shaded conditions. Moreover, taller trees could more easily access deeper soil water with their more developed root system, thus operating at overall better soil moistures than small trees, at least under average conditions. 

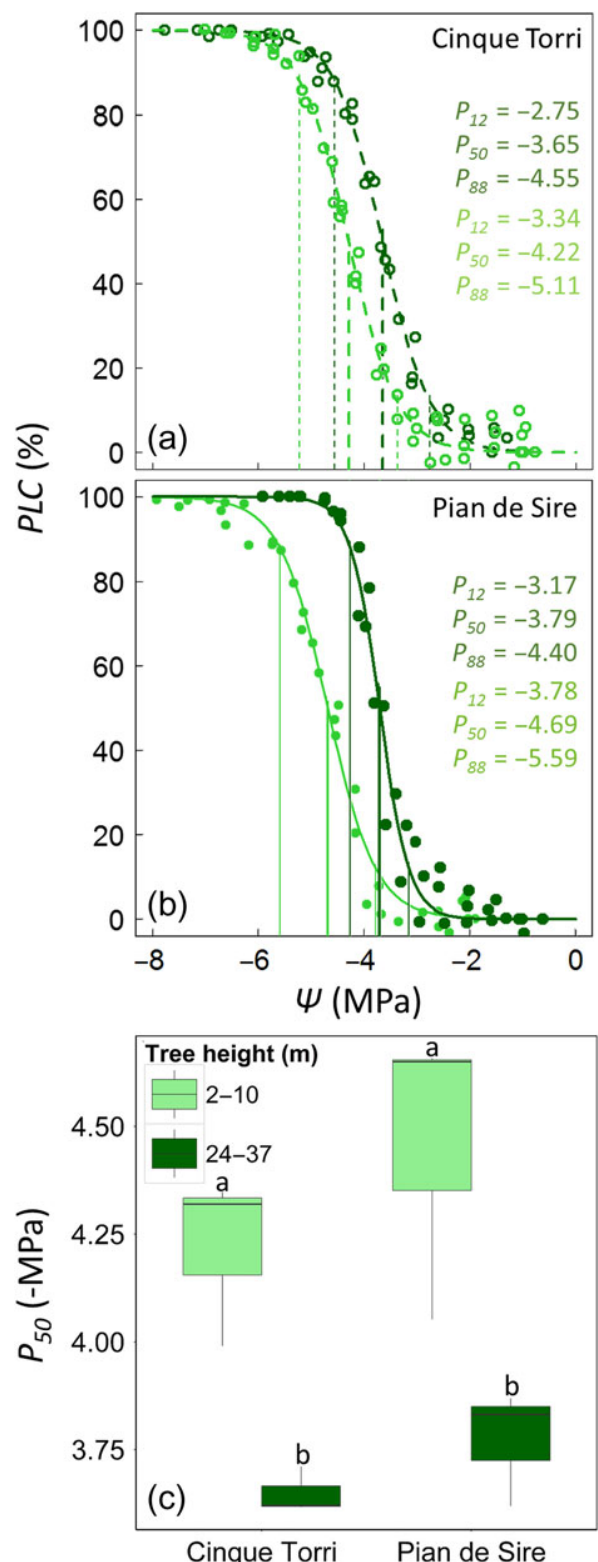

Figure 3. (a, b) Mean vulnerability curves (percentage loss of conductivity $(P L C)$ vs xylem water potential $(\Psi)$ ) of three apical shoots within the smallest (light green symbols) and the tallest (dark green symbols) Picea abies trees from Cinque Torri (open symbols, dashed lines, a) and Pian de Sire (filled symbols, solid lines, b) (in total 12 trees were considered). Each curve represents an aggregate of three samples from the respective treesize/site class. Fitted curves were estimated according to a logistic function (Pammenter and Van der Willigen 1998), where $\Psi$ at $P L C=50 \%$ $\left(P_{50}\right)$ is represented by thick vertical lines and $\Psi$ at $P L C=12 \%\left(P_{12}\right)$ and $\Psi$ at $P L C=88 \%\left(P_{88}\right)$ by thin lines. (c) Differences in $P_{50}$ between the same individuals as in $(a, b)$. Tree height range of smallest $(2-10 \mathrm{~m})$ and tallest trees $(24-37 \mathrm{~m}$ ) are characterized by light and dark green colors, respectively. Letters indicate significant differences of $P_{50}$ based on Tukey's Honest Significant Difference test.

In our trees, apical conductance increased with tree height not only because of the effect of wider tracheids but also because of the effect of increasing number of tracheids $(\mathrm{Cn})$, as we observed at the Pian de Sire site (Figure 2). These results
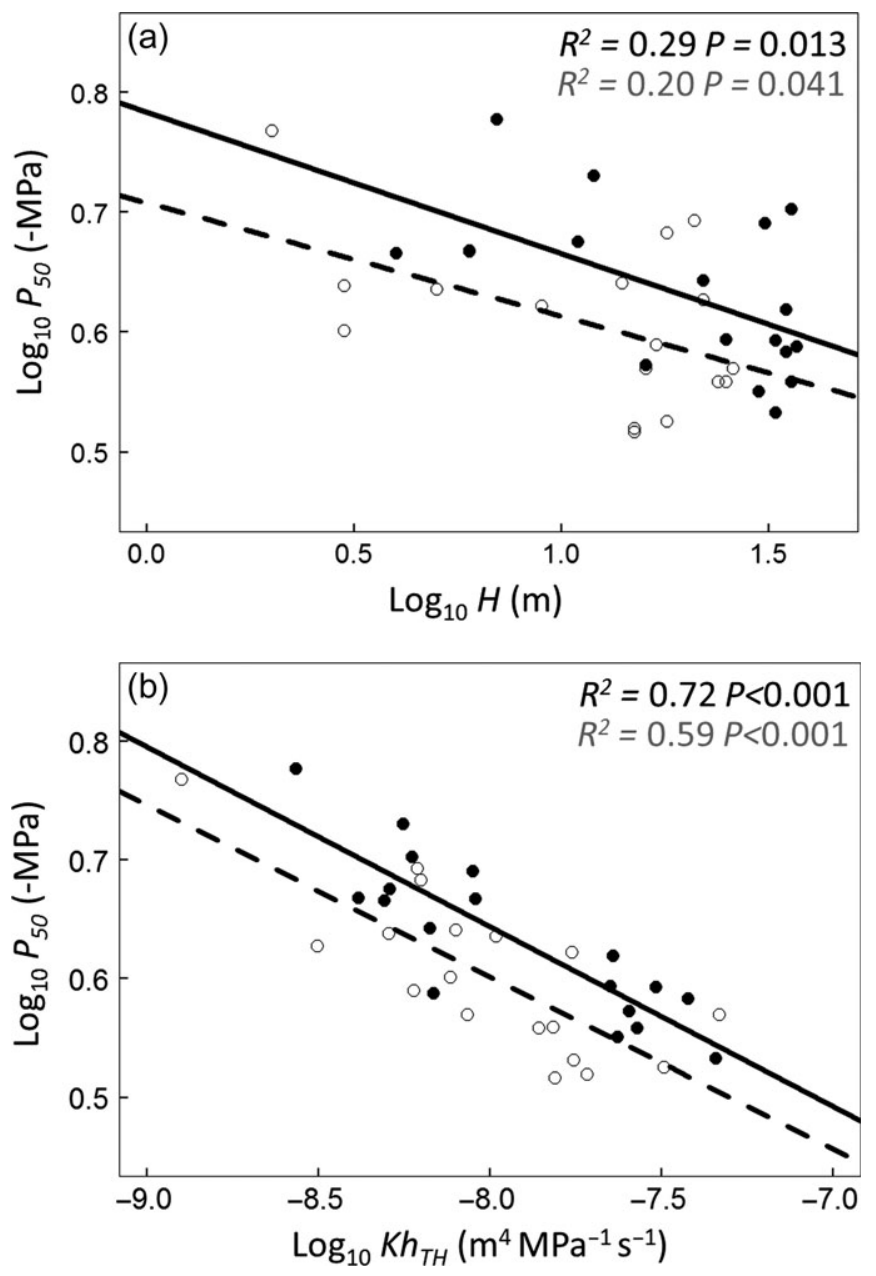

Figure 4. Relationships between (a) $P_{50}$ and tree height $(H)$ and (b) $P_{50}$ and $K h_{\mathrm{TH}}$. Data are $\log _{10}$-transformed. Filled and open circles represent Pian de Sire and Cinque Torri data, respectively. Solid and dashed lines represent the fitted linear regressions for Pian de Sire and Cinque Torri, respectively. See Table 1 for details on statistical model output for (a).

supported our primary hypothesis that the apex of taller trees undergoes anatomical adjustments aimed to increase its hydraulic conductivity. At the same time, xylem vulnerability (less negative $P_{50}$ ) increased with tree height (Figure 4). Although there seemed to be no straightforward link between tracheid size and vulnerability to air seeding in conifers, such a result is not completely novel (e.g., Pittermann et al. 2006, Larter et al. 2017). According to Cochard et al. (2009) and Delzon et al. (2010), air bubbles probably enter conduits when the sealing between torus and pit border fails via seal capillaryseeding (also see Hacke and Jansen 2009, Bouche et al. 2014). Alternatively, air may enter via small pores within the torus of some species (Jansen et al. 2012). In this respect, it has been recently reported that pit aperture scales isometrically with tracheid diameter (Lazzarin et al. 2016). Therefore, it is reasonable that our larger tracheids are also more vulnerable to air seeding; however, further investigation is still required to provide additional evidence on possible safety-efficiency trade-offs at 


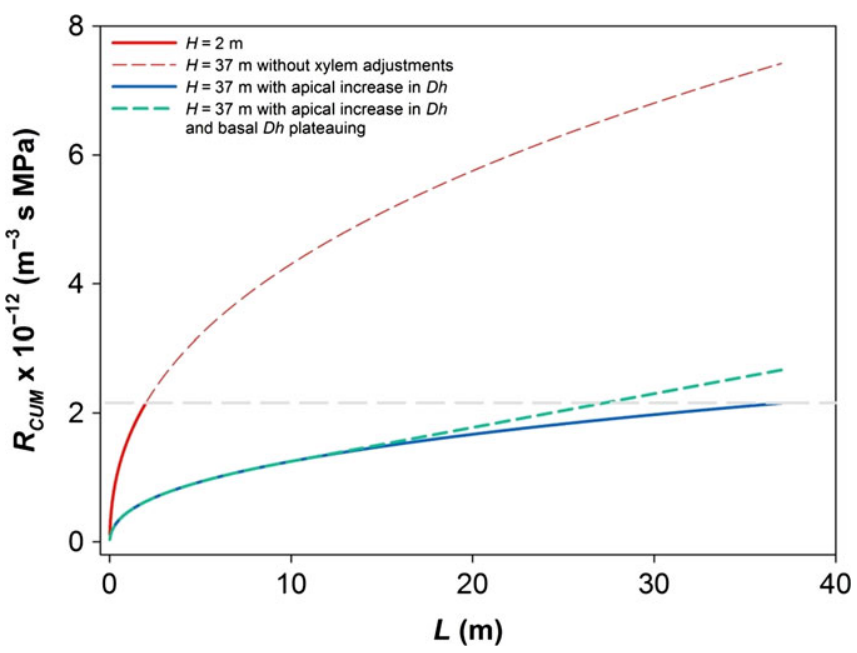

Figure 5. Variation in cumulative hydraulic resistance ( $\left.R_{\text {CUM }}\right)$ along the stem axis from apex to base, assessed as the sum of the single conduit resistances calculated according to the Hagen-Poiseuille equation (conduit length was assumed as $1 \mathrm{~cm}$ ) and connected in series. The red solid line shows the increase in $R_{\text {CUM }}$ for a tree of $H=2 \mathrm{~m}$ modeled according to a pattern of axial conduit widening $\left(D h=a \cdot L^{b}\right)$ with an average widening factor of $b=0.15$ and $a$ assessed as for $D h$ at $10 \mathrm{~cm}$ being equal to the empirical estimates in this study $\left(D h_{10 \mathrm{~cm}}=10.92 \mu \mathrm{m}\right)$. The red dashed line shows the further increase in $R_{\text {CUM }}$ with $L$ for a $37 \mathrm{~m}$ tall tree with no anatomical adjustments (i.e., same $a$ and $b$ as the $2 \mathrm{~m}$ tall tree). The blue solid line represents the increase in $R_{\text {CUM }}$ for a $37 \mathrm{~m}$ tall tree characterized by the same $b=0.15$ and wider apical conduits according to the empirical observations in this study $\left(D h_{10 \mathrm{~cm}}=14.88 \mu \mathrm{m}\right)$. The green dashed line represents the increase in $R_{\text {CUM }}$ for tree with same characteristic of height, $D h_{10 \mathrm{~cm}}$ and $b=0.15$ until $L=10 \mathrm{~m}$ and no further increase in $D h$ below (basal plateau effect). Data of $R_{\text {CUM }}$ are presented relative to the total hydraulic resistance for the modeled tree of $2 \mathrm{~m}$ (reference gray dashed line).

the pit level (Wheeler et al. 2005, Hacke et al. 2006) or to support previous findings of opposing trends between height and pit aperture and conduit diameter (Burgess et al. 2006).

Compared with other studies reporting results on the effect of height on xylem vulnerability to air seeding, our research features two important novelties: (i) we measured the actual leader shoot of trees differing in height, and (ii) we took measurements at a fixed distance from the apex to account for potential axial scaling of xylem properties, such as the increase in lumen diameter (Anfodillo et al. 2013) and pit aperture (Lazzarin et al. 2016) along the stem. The latter standardization protocol is intrinsically different from the one more commonly used for hydraulic measurements, e.g., taken on branches of similar age to avoid the potential age effects on hydraulic properties, or the effect of repeated cycles of cavitation and refilling (cavitation fatigue) across different growing seasons (Hacke et al. 2001b), and therefore not accounting for the axial patterns of anatomical traits.

Evidence from the literature seems rather variable on the pattern of xylem vulnerability in different branches along the stem. For instance, it has been found that side branches of Norway spruce trees have a higher vulnerability compared with leader shoots (Mayr et al. 2003). Moreover, the vulnerability to cavitation was found to decrease from lower to upper branches in very tall trees (Burgess et al. 2006, Domec et al. 2009), but also to increase in smaller juniper trees (Beikircher and Mayr 2008).

On a conceptual basis, our results that taller trees prioritize efficiency over safety are in striking contrast to the study by Domec et al. (2008), who found a higher cavitation resistance in the upper branches in the world's tallest trees. In that study, the reduced vulnerability was associated with a reduction in pit permeability, suggesting the priority for xylem safety over efficiency with increasing hydraulic constraint following height growth. Similar results were obtained by Ambrose et al. (2009), who measured the vulnerability of upper branches in trees widely varying in size. However, in contrast to these studies, we accounted for the possible effects of anatomical adjustment of branch xylem along the stem (axial scaling of anatomical traits). Therefore, it would be desirable to test whether hydraulic measurements at fixed distance from the apex on leader shoots (or most apical branches) of trees varying from seedlings to maximum height in the world's tallest conifer and angiosperm species would present similar patterns to the ones we have found.

Even though we observed lower embolism resistance in the apex of the tallest trees, their actual risk of air seeding might overall still be relatively low, if, for instance, they likely have better access to soil water with their larger and deeper root systems (Rosner 2013). However, apical shoots must increase their conductance to overcome the increased biophysical limitations to water flow arising from the increase in tree height, even if it is at the cost of reduced embolism resistance. Such a result opens a new perspective on the higher susceptibility of taller trees to drought events (Nepstad et al. 2007, McDowell et al. 2008, Lewis et al. 2011, Rowland et al. 2015). Indeed, leaf water potential was found to decrease with tree height because of (i) gravity (Koch et al. 2004, Burgess and Dawson 2007), (ii) increasing path length and (iii) corresponding total resistance (unless compensated by anatomical adjustments to increase apical conductance). For these reasons, the hydraulic safety margin against cavitation $\left(S M=P_{50}-\Psi_{\mathrm{MIN}}\right.$, where $\Psi_{\mathrm{MIN}}$ is the minimum leaf water potential) (Choat et al. 2012) should decrease with tree height. As a consequence, the top of taller trees could be exposed to higher risks of embolism formation and xylem dysfunction under drought (Figure 6). However, trees might also respond by adjusting water potential and thus safety margins by stomatal regulation. Further investigations are required to understand the critical balance of hydraulic safety, hydraulic efficiency and carbon acquisition in taller trees, and to analyse if the prioritization of hydraulic efficiency vs safety in taller trees is indeed a pattern common to both conifers and angiosperms in different environments.

This study presents new perspectives on the fundamental strategies used by trees as they adjust to height increases. Our 


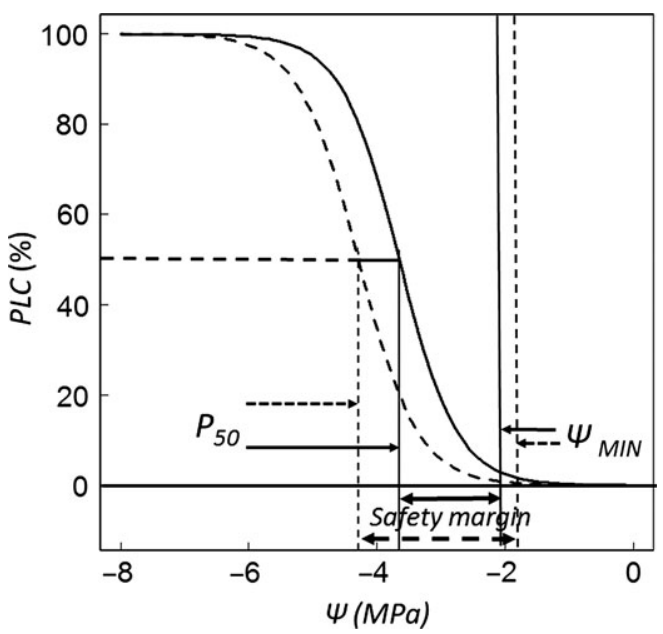

Figure 6. Vulnerability curves (VCs: data from Figure 3a) and minimum leaf water potential ( $\Psi_{\mathrm{MIN}}$ : denoted by vertical lines) in tall (solid lines) and small trees (dashed lines). $\Psi_{\text {MIN }}$ are average values from the literature (Choat et al. 2012) adjusted for the gravitational effect of $-0.01 \mathrm{MPa} \mathrm{m}^{-1}$ (Koch et al. 2004). Horizontal arrows represent the hydraulic safety margin $\left(=\Psi_{\mathrm{MIN}}-P_{50}\right)$.

results suggest that tall trees build more efficient and conductive xylem at the treetop that likely promotes and sustains leaf gas exchanges under impeding height-related hydraulic limitations. As our observations also suggest tall trees may have higher vulnerability to air seeding, future studies are needed to confirm how anatomical adjustments maintain the functional balance between sapflow and leaf transpiration rates, and thus allow a tree to maintain a positive carbon balance and guarantee its survival.

\section{Supplementary Data}

Supplementary data for this article are available at Tree Physiology Online.

\section{Acknowledgments}

We thank Birgit Dämon, Innsbruck University, Botanic Institute, for valuable assistance during vulnerability measurements, Maria Elena Gelain, Department of Comparative Biomedicine and Food Safety, University of Padua, for providing access to the D-sight 2.0 System automatic scanner used for micro-section imaging, and Daniel Balanzategui, German Research Centre for Geosciences, Potsdam, for English proofreading. Many thanks to editor Jordi Martínez-Vilalta, Sean M. Gleason and two anonymous reviewers for constructive comments on earlier versions of this manuscript.

\section{Conflict of interest}

None declared.

\section{Funding}

A.L.P. was partially supported by the 2017 BIRD Project of TeSAF Department University of Padova, G.v.A. was supported by a grant from the Swiss State Secretariat for Education, Research and Innovation SERI (SBFI C14.0104). Parts of the study were supported by a Sparkling Science Project funded by the Federal Ministry of Science, Research and Economy (Bundesministerium für Wissenschaft, Forschung und Wirtschaft) Austria, and a Hertha-Firnberg Project (T667-B16 'Hydraulics of juvenile trees') funded by the Austrian Science Fund (FWF).

\section{Authors' contributions}

A.L.P., S.M., B.B. and G.P. planned and designed the research, and A.L.P. and G.P. conducted the fieldwork. A.L.P. performed laboratory work. A.L.P., G.v.A. and G.P. analyzed the data. A.L.P. led the manuscript drafting with contributions from GP. All authors critically revised the manuscript.

\section{References}

Ambrose AR, Sillett SC, Dawson TE (2009) Effects of tree height on branch hydraulics, leaf structure and gas exchange in California redwoods. Plant Cell Environ 32:743-757.

Anfodillo T, Carraro V, Carrer M, Fior C, Rossi S (2006) Convergent tapering of xylem conduits in different woody species. New Phytol 169:279-290.

Anfodillo T, Petit G, Crivellaro A (2013) Axial conduit widening in woody species: a still neglected anatomical pattern. IAWA J 34:352-364.

Becker P, Gribben R, Schulte PJ (2003) Incorporation of transfer resistance between tracheary elements into hydraulic resistance models for tapered conduits. Tree Physiol 23:1009-1019.

Beikircher B, Mayr S (2008) The hydraulic architecture of Juniperus communis L. ssp. communis: shrubs and trees compared. Plant Cell Environ 31:1545-1556.

Beikircher B, Ameglio T, Cochard H, Mayr S (2010) Limitation of the Cavitron technique by conifer pit aspiration. J Exp Bot 61: 3385-3393.

Bettiati D, Petit G, Anfodillo T (2012) Testing the equi-resistance principle of the xylem transport system in a small ash tree: empirical support from anatomical analyses. Tree Physiol 32:171-177.

Bouche PS, Larter M, Domec JC, Burlett R, Gasson P, Jansen S, Delzon S (2014) A broad survey of hydraulic and mechanical safety in the xylem of conifers. J Exp Bot 65:4419-4431.

Burgess SSO, Dawson TE (2007) Predicting the limits to tree height using statistical regressions of leaf traits. New Phytol 174:626-636.

Burgess SSO, Pittermann J, Dawson TE (2006) Hydraulic efficiency and safety of branch xylem increases with height in Sequoia sempervirens (D. Don) crowns. Plant Cell Environ 29:229-239.

Choat B, Jansen S, Brodribb TJ et al. (2012) Global convergence in the vulnerability of forests to drought. Nature 491:752-755.

Cochard H (2002) A technique for measuring xylem hydraulic conductance under high negative pressures. Plant Cell Environ 25:815-819.

Cochard H, Hölttä T, Herbette S, Delzon S, Mencuccini M (2009) New insights into the mechanisms of water-stress-induced cavitation in conifers. Plant Physiol 151:949-954.

Cochard H, Badel E, Herbette S, Delzon S, Choat B, Jansen S (2013) Methods for measuring plant vulnerability to cavitation: a critical review. J Exp Bot 64:4779-4791. 
Delzon S, Douthe C, Sala A, Cochard H (2010) Mechanism of waterstress induced cavitation in conifers: bordered pit structure and function support the hypothesis of seal capillary-seeding. Plant Cell Environ 33:2101-2111.

Domec J-C, Lachenbruch B, Meinzer FC, Woodruff DR, Warren JM, McCulloh KA (2008) Maximum height in a conifer is associated with conflicting requirements for xylem design. Proc Natl Acad Sci USA 105:12069-12074.

Domec J-C, Warren JM, Meinzer FC, Lachenbruch B (2009) Safety factors for xylem failure by implosion and air-seeding within roots, trunks and branches of young and old conifer trees. IAWA J 30:101-120.

Enquist BJ (2003) Cope's rule and the evolution of long-distance transport in vascular plants: allometric scaling, biomass partitioning and optimization. Plant Cell Environ 26:151-161.

Gleason SM, Westoby M, Jansen S et al. (2016) Weak tradeoff between xylem safety and xylem-specific hydraulic efficiency across the world's woody plant species. New Phytol 209:123-136.

Hacke UG, Jansen S (2009) Embolism resistance of three boreal conifer species varies with pit structure. New Phytol 182:675-686.

Hacke UG, Sperry JS (2001) Functional and ecological xylem anatomy. Perspect Plant Ecol Syst 4:97-115.

Hacke UG, Sperry JS, Pockman WT, Davis SD, McCulloh KA (2001a) Trends in wood density and structure are linked to prevention of xylem implosion by negative pressure. Oecologia 126:457-461.

Hacke UG, Stiller V, Sperry JS, Pittermann J, McCulloh KA (2001b) Cavitation fatigue. Embolism and refilling cycles can weaken the cavitation resistance of xylem. Plant Physiol 125:779-786.

Hacke UG, Sperry JS, Wheeler JK, Castro L (2006) Scaling of angiosperm xylem structure with safety and efficiency. Tree Physiol 26:689-701.

Jansen S, Lamy J, Burlett R, Cochard H, Gasson P, Delzon S (2012) Plasmodesmatal pores in the torus of bordered pit membranes affect cavitation resistance of conifer xylem. Plant Cell Environ 35:1109-1120.

Koch GW, Sillett SC, Jennings GM, Davis SD (2004) The limits to tree height. Nature 428:851-854.

Larter M, Pfautsch S, Domec JC, Trueba S, Nagalingum N, Delzon S (2017) Aridity drove the evolution of extreme embolism resistance and the radiation of conifer genus Callitris. New Phytol 215:97-112.

Lazzarin M, Crivellaro A, Williams CB, Dawson TE, Mozzi G, Anfodillo T (2016) Tracheid and pit anatomy vary in tandem in a tall Sequoiadendron giganteum tree. IAWA J 37:172-185.

Lewis SL, Brando PM, Phillips OL, van der Heijden GMF, Nepstad D (2011) The 2010 Amazon drought. Science 331:554.

Mäkelä A, Valentine HT (2006) Crown ratio influences allometric scaling in trees. Ecology 87:2967-2972.

Mayr S, Wolfschwenger M, Bauer H (2002) Winter-drought induced embolism in Norway spruce (Picea abies) at the Alpine timberline. Physiol Plant 115:74-80.

Mayr S, Rothart B, Dämon B (2003) Hydraulic efficiency and safety of leader shoots and twigs in Norway spruce growing at the alpine timberline. J Exp Bot 54:2563-2568.

Mayr S, Cochard H, Ameglio T, Kikuta SB (2007) Embolism formation during freezing in the wood of Picea abies. Plant Physiol 143:60-67.

McCulloh KA, Sperry JS (2005) Patterns in hydraulic architecture and their implications for transport efficiency. Tree Physiol 25:257-267.

McDowell N, Pockman WT, Allen CD et al. (2008) Mechanisms of plant survival and mortality during drought: why do some plants survive while others succumb to drought? New Phytol 178:719-739.

Meinzer FC, Lachenbruch B, Dawson TE (2011) Photosyntetic gas exchange and carbon balance. In: Meinzer FC, Lachenbruch B, Dawson TE (eds) Size- and age-related changes in tree structure and function. Springer, Dordrecht, Netherlands, pp 235-306.

Mencuccini M, Hölttä T, Petit G, Magnani F (2007) Sanio's laws revisited. Size-dependent changes in the xylem architecture of trees. Ecol Lett 10:1084-1093.
Nardini A, Savi T, Losso A et al. (2017) X-ray microtomography observations of xylem embolism in stems of Laurus nobilis are consistent with hydraulic measurements of percentage loss of conductance. New Phytol 213:1068-1075.

Nepstad DC, Tohver IM, David R, Moutinho P, Cardinot G (2007) Mortality of large trees and lianas following experimental drought in an Amazon forest. Ecology 88:2259-2269.

Olson ME, Anfodillo T, Rosell JA, Petit G, Crivellaro A, Isnard S, León-Gómez C, Alvarado-Cárdenas LO, Castorena M (2014) Universal hydraulics of the flowering plants: vessel diameter scales with stem length across angiosperm lineages, habits and climates. Ecol Lett 17:988-997.

Pammenter NW, Van der Willigen C (1998) A mathematical and statistical analysis of the curves illustrating vulnerability of xylem to cavitation. Tree Physiol 18:589-593.

Petit G, Anfodillo T (2009) Plant physiology in theory and practice: an analysis of the WBE model for vascular plants. J Theor Biol 259:1-4.

Petit G, Anfodillo T, Mencuccini M (2008) Tapering of xylem conduits and hydraulic limitations in sycamore (Acer pseudoplatanus) trees. New Phytol 177:653-664.

Petit G, Pfautsch S, Anfodillo T, Adams MA (2010) The challenge of tree height in Eucalyptus regnans: when xylem tapering overcomes hydraulic resistance. New Phytol 187:1146-1153.

Petit G, Anfodillo T, Carraro V, Grani F (2011) Hydraulic constraints limit height growth in trees at high altitude. New Phytol 189:241-252.

Petit G, Savi T, Consolini M, Anfodillo T, Nardini A (2016) Interplay of growth rate and xylem plasticity for optimal coordination of carbon and hydraulic economies in Fraxinus ornus trees. Tree Physiol 36: 1310-1319.

Pittermann J, Sperry JS, Wheeler JK, Hacke UG, Sikkema EH (2006) Mechanical reinforcement of tracheids compromises the hydraulic efficiency of conifer xylem. Plant Cell Environ 29:1618-1628.

Prendin AL, Petit G, Fonti P, Rixen C, Dawes MA, von Arx G (2017a) Axial xylem architecture of Larix decidua exposed to $\mathrm{CO}_{2}$ enrichment and soil warming at the tree line. Funct Ecol 32:273-287.

Prendin AL, Petit G, Carrer M, Fonti P, Björklund J, von Arx G (2017b) New research perspectives from a novel approach to quantify tracheid wall thickness. Tree Physiol 37:976-983.

R Development Core Team (2014) R: A language and environment for statistical computing. R Foundation for Statistical Computing, Vienna, Austria.

Rosner S (2013) Hydraulic and biomechanical optimization in Norway spruce trunkwood-a review. IAWA J 34:365-390.

Rowland L, da Costa ACL, Galbraith DR, Binks OJ, Oliveira AAR, Pullen AM, Meir P (2015) Death from drought in tropical forests is triggered by hydraulics not carbon starvation. Nature 528:119-122.

Ryan MG, Yoder BJ (1997) Hydraulic limits to tree height and tree growth. Bioscience 47:235-242.

Savage VM, Bentley LP, Enquist BJ, Sperry JS, Smith DD, Reich PB, von Allmen El (2010) Hydraulic trade-offs and space filling enable better predictions of vascular structure and function in plants. Proc Natl Acad Sci USA 107:22722-22727.

Sperry JS, Hacke UG, Pittermann J (2006) Size and function in conifer tracheids and angiosperm vessels. Am J Bot 93:1490-1500.

Tyree M, Ewers F (1991) The hydraulic architecture of trees and other woody plants. New Phytol 119:345-360.

Tyree MT, Sperry JS (1989) Vulnerability of xylem to cavitation and embolism. Annu Rev Plant Physiol Plant Mol Biol 40:19-36.

Tyree MT, Zimmermann MH (2002) Conducting units: Tracheids and Vessels 1-25 and Xylem dysfunction: when cohesion breaks down. In: Xylem structure and the ascent of sap. Springer-Verlag, Berlin, Heidelberg, New York, pp 89-141.

Venturas MD, Sperry JS, Hacke UG (2017) Plant xylem hydraulics: What we understand, current research, and future challenges. J Integr Plant Biol 59:356-389. 
von Arx G, Carrer M (2014) ROXAS - a new tool to build centuries-long tracheid-lumen chronologies in conifers. Dendrochronologia 32: 290-293.

von Arx G, Crivellaro A, Prendin AL, Čufar K, Carrer M (2016) Quantitative wood anatomy — practical guidelines. Front Plant Sci 7:781.

von Arx G, Dietz H (2005) Automated image analysis of annual rings in the roots of perennial forbs. Int J Plant Sci 166:723-732.

West GB, Brown JH, Enquist BJ (1999) A general model for the structure and allometry of plant vascular systems. Nature 400: 664-667.

Wheeler JK, Sperry JS, Hacke UG, Hoang N (2005) Inter-vessel pitting and cavitation in woody Rosaceae and other vessel led plants: a basis for a safety versus efficiency trade-off in xylem transport. Plant Cell Environ 28:800-812.

Willson CJ, Jackson RB (2006) Xylem cavitation caused by drought and freezing stress in four co-occurring Juniperus species. Physiol Plant 127:374-382.

Zar JH (2010) Biostatistical analysis, 5th edn. Prentice-Hall, Upper Saddle River, NJ, USA, Chapter 13, pp 286-295.

Zhang Y-J, Rockwell FE, Graham AC, Alexander T, Holbrook NM (2016) Reversible leaf xylem collapse: a potential 'circuit breaker' against cavitation. Plant Physiol 172:2261-2274.

Zuur AF, leno EN, Elphick CS (2010) A protocol for data exploration to avoid common statistical problems. Methods Ecol Evol 1:3-14. 


\section{Supplementary material}

2

3 Figure S1: Relationship of $K h_{T H}$ (assessed from anatomical measurements, thus only considering

4 lumen resistance) with $K h_{\text {MAX }}$ (assessed from hydraulic measurements, thus considering both lumen

5 and pit resistance). The leader shoot segments for the hydraulic measurements in most cases had a larger xylem area (on average 65\% larger) at the lower (inflow) than upper (outflow) end $(P<0.001)$ and encompassed two to five internodes. This means that more tracheids were likely present at the segment base than at the apex. In addition, tracheid diameters at the upper end have a reduced size compared to the ones at the lower end due to the tracheid widening. Therefore, the theoretical $K h_{T H}$ assessed from the anatomical measurements taken at the outflow is as expected slightly lower than the $K h_{\text {MAX }}$ measured with the Cavitron even if ignoring the pit resistance. Moreover, in few samples, the outermost part of the xylem (latewood last ring) was partially removed to fit the shoot base in the cuvette, which likely determined a more scattered relationship between $K h_{T H}$ and $K h_{M A X}$.

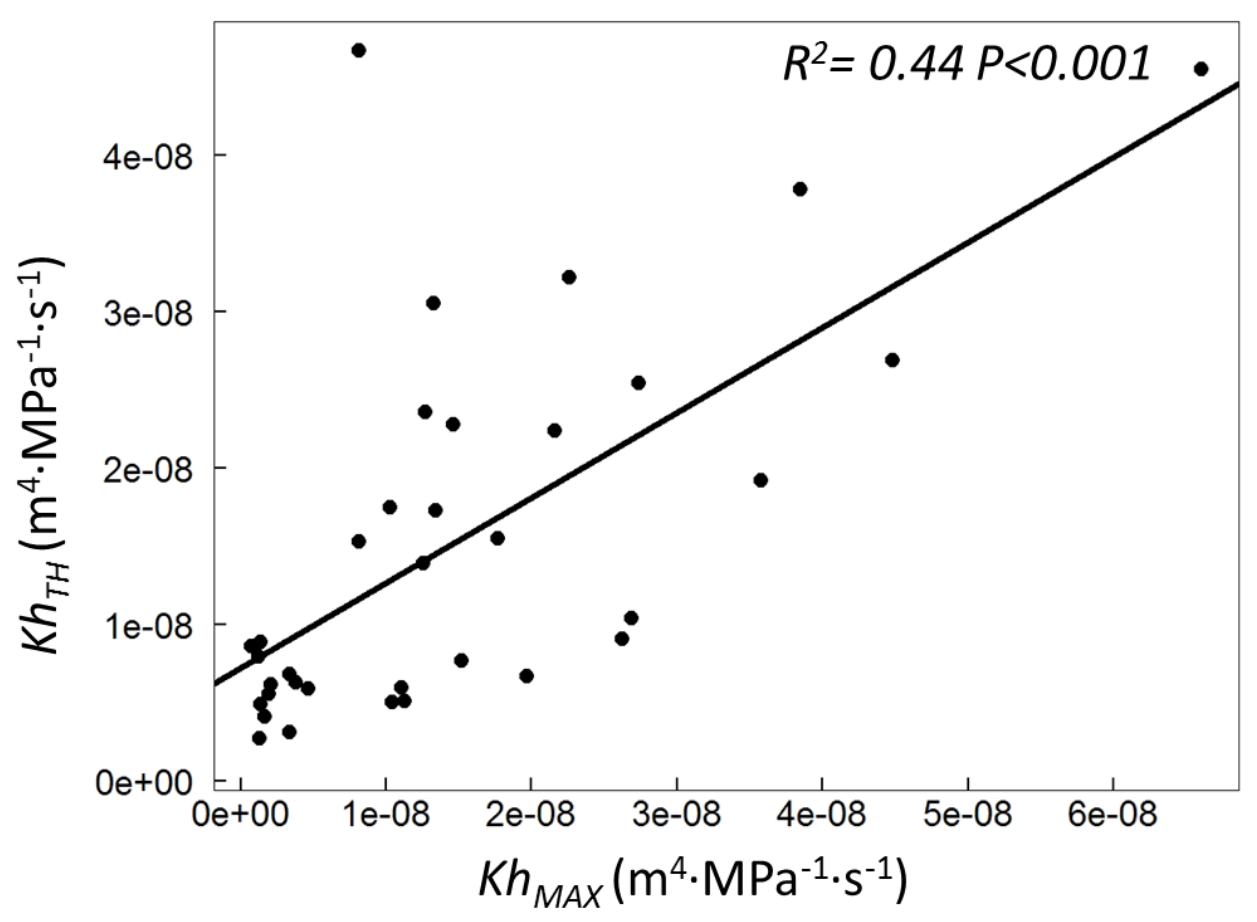



transformed. Filled and open circles represent Pian de Sire and Cinque Torri data, respectively. Solid and dashed lines represent the fitted linear regressions for Pian de Sire and Cinque Torri, respectively. See Table

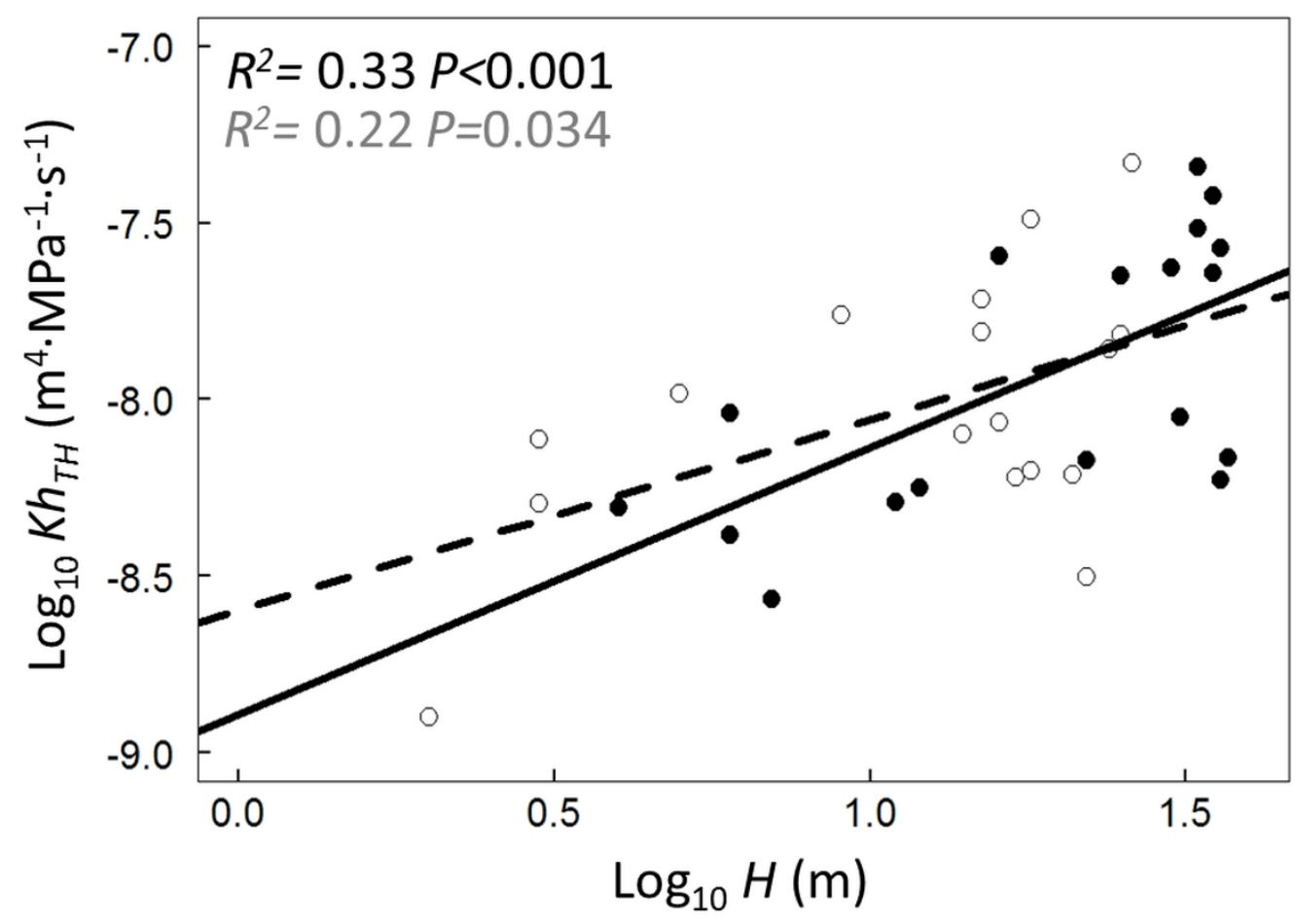


